\title{
Heat shock-mediated regulation of IкB- $\alpha$ at the post-transcriptional level by HuR
}

\author{
YUXIN LIU ${ }^{1 *}$ and WENYAN YU ${ }^{2,3 *}$ \\ ${ }^{1}$ Department of Histology, The Medical School, Ningbo University, Ningbo, Zhejiang 315211; \\ ${ }^{2}$ Department of Pathophysiology, Southern Medical University, Guangzhou, Guangdong 510515; ${ }^{3}$ Department of \\ Pathophysiology, Xinjiang Medical University, Urumuqi, Xinjiang 830000, P.R. China
}

Received March 1, 2013; Accepted June 11, 2013

DOI: $10.3892 / \mathrm{mmr} .2013 .1820$

\begin{abstract}
Heat shock treatment induces tolerance to subsequent thermal stress and abrogates the response to alternative stimuli, including LPS and cytokines in vitro and in vivo. One of the mechanisms responsible for this phenomenon is inhibition of the nuclear factor $-\kappa \mathrm{B}(\mathrm{NF}-\kappa \mathrm{B})$ pathway via

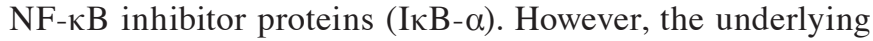
mechanisms involved in the effect of heat shock treatment on I $\kappa \mathrm{B}-\alpha$ expression remain unclear. In the present study, the effect of heat shock treatment on the production of IкB- $\alpha$ and the possible mechanisms involved were investigated. The results revealed a significant increase in the half-lives of I $\kappa \mathrm{B}-\alpha$ mRNA and proteins in RAW264.7 macrophages following heat shock treatment and $\mathrm{I} \kappa \mathrm{B}-\alpha$ transcription levels also increased. In addition, RNA pull-down and RNA immunoprecipitation studies showed that the RNA-binding protein, HuR, may specifically bind to the I $\kappa$ B- $\alpha$ mRNA 3'UTR upon heat shock treatment. Overexpression of HuR in 3T3 cells caused an alteration in $\mathrm{I} \kappa \mathrm{B}-\alpha$ protein expression leading to a change in NF- $\kappa \mathrm{B}$ expression, however, I $\kappa \mathrm{B}-\alpha$ mRNA expression levels were unchanged. The relocalization of HuR from the nucleus to the cytoplasm was observed following $1 \mathrm{~h}$ heat shock treatment and HuR was colocalized with the G3BP1 protein, the main content of stress granules. The results indicate that following heat shock treatment, HuR translocates from the nucleus to the cytoplasm, forming stress granules and regulating the translation of $\mathrm{I} \kappa \mathrm{B}-\alpha$ mRNA without affecting the half-life.
\end{abstract}

Correspondence to: Professor Yuxin Liu, Department of Histology, The Medical School, Ningbo University, 818 Fenghua Road, Ningbo, Zhejiang 315211, P.R. China

E-mail: liuyuxin@nbu.edu.cn

${ }^{*}$ Contributed equally

Key words: HuR, IкB- $\alpha, \mathrm{NF}-\kappa \mathrm{B}$, post-transcriptional, heat shock

\section{Introduction}

Heat shock treatment protects against a variety of cell and tissue injuries, including sepsis, acute lung injury, ischemia reperfusion injury and endotoxin-mediated apoptosis (1). One of the mechanisms by which heat shock treatment induces tolerance is via the inhibition of key signaling pathways, including nuclear factor $\mathrm{\kappa B}(\mathrm{NF}-\mathrm{\kappa B})$, which transcriptionally regulate stress-response genes. Heat shock treatment has been demonstrated to inhibit activation of the NF- $\mathrm{KB}$ pathway by mechanisms involving inhibition of the inhibitor of NF- $\mathrm{KB}$ (IкB) kinase activation (2-4). Heat shock has also been demonstrated to increase the mRNA stability of a number of genes $(5,6)$.

NF- $\mathrm{KB}$ is a critical transcription factor involved in a broad range of biological processes, including immune responses, cell survival, stress responses and maturation of various cell types. NF- $\mathrm{kB}$ activation is required to protect organisms from environmental factors, however, deregulated NF- $\mathrm{kB}$ activity has been observed in various diseases, including chronic inflammation and cancer. Thus, understanding the regulation of NF- $\mathrm{KB}$ signaling is important for maintaining human health.

The I $\mathrm{B}$ proteins are important for the regulation of $\mathrm{NF}-\kappa \mathrm{B}$ signaling. The classical inhibitor proteins in the NF- $\mathrm{KB}$

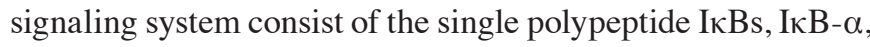

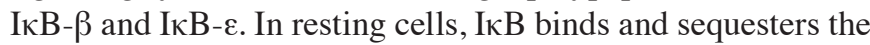
$\mathrm{NF}-\mathrm{\kappa B}$ dimer and prevents DNA binding and transcriptional activation. Stimulus-responsive activation of the ІкB kinase results in the degradation of the IкBs to release and activate NF- $\mathrm{BB}(4)$.

From these observations, the mechanism by which heat shock treatment modulates NF- $\kappa$ B signaling cascades was investigated, in particular the Iк-B $\alpha$ gene expression with a focus on post-transcriptional regulation.

\section{Materials and methods}

Cell culture and heat shock. NIH 3T3 and RAW264.7 murine macrophages (American Type Culture Collection, Manassas, VA, USA) were cultured in DMEM (Gibco-BRL, Carlsbad, CA, USA) supplemented with $10 \%$ fetal bovine serum (Gibco-BRL) in a $95 \%$ room air-5\% $\mathrm{CO}_{2}$ incubator at $37^{\circ} \mathrm{C}$. Heat shock treatment was performed by incubating cells at 
$43^{\circ} \mathrm{C}$ for $1 \mathrm{~h}$ in a $95 \%$ room air- $5 \% \mathrm{CO}_{2}$ incubator with subsequent return to $37^{\circ} \mathrm{C}$.

Plasmid construction. Mouse (flag)-tagged HuR and the pRL-TK plasmid were used. Full-length HuR mRNA 3'UTR was amplified using specific primers and cloned into the pcDNA3-flag vector (Promega, Madison, WI, USA) using the $K p n I$ and $X b a \mathrm{I}$ sites. The following primers were used: sense, 5'-GTGGTACCA TGTCTAATGGTTATGAAGACCAC-3' and anti-sense, 5'-GCTCTAGAGCTGTCTGTAAAAATCT GTTTAAT-3'. Full-length I $\kappa$ B- $\alpha$ mRNA 3'UTR was amplified using specific primers and cloned into the pGL3 vector (Promega) using the $\mathrm{XbaI}$ and $\mathrm{NcoI}$ sites and named pLuNB. The following primers were used: sense, 5'-ATCGCCGTGTAATGGAAAGTGGCAAAAAG AATG-3' and anti-sense, 5'-GCTCTAGAGCTGTCTGTAAA AATCTGTTTAAT-3'.

Transient transfection. pLuNB and control plasmids were transfected using Lipofectamine 2000 ${ }^{\mathrm{TM}}$ (Invitrogen Life Technologies, Carlsbad, CA, USA). Transfected cells were used for analysis $48 \mathrm{~h}$ following transfection.

Luciferase assays. Cells were transfected and cultured in six-well plates at a density of $3 \times 10^{5}$ cells/well. Following $1 \mathrm{~h}$ heat shock, cells were washed with PBS once and cellular proteins were extracted and analyzed for luciferase activity according to the manufacturer's instructions (Promega $\mathrm{GmbH}$ ) with the use of a luminometer (SpectarMax M5, Molecular Devices, Sunnyvale, CA, USA). Luciferase activity was corrected for total cellular protein and reported as relative induction over respective control cells (cells that were transfected with pGL3 control plasmid).

RNAinterference.Amixture of smallinterfering RNAs(siRNAs; $25 \mathrm{nM}$; GenePharma, Shanghai, China) specifically targeting HuR was transfected into cells using Lipofectamine 2000. The following sets of primers were used: Elavl1-mus-360 sense, 5'-GCGAGGUUGAAUCUGCAAATT-3' and antisense, 5'-UUUGCAGAUUCAACCUCGCTT-3'; Elavl1-mus-1099 sense, 5'-GACCAUGACAAACUAUGAATT-3' and antisense, 5'-UUCAUAGUUUGUCAUGGUCTT-3'; Elavl1-mus-522 sense, 5'-CAAGCUCAGAGGUCAUCAATT-3' and antisense 5'-UUGAUGACCUCUGAGCUUGTT-3'.

RNP immunoprecipitation (IP) assays. For the IP assay of endogenous RNA-protein complexes from whole-cell extracts, cell lysates were incubated with protein A-Sepharose beads (Sigma-Aldrich, St. Louis, MO, USA) that had been precoated with $30 \mu \mathrm{g}$ mouse immunoglobulin G1 (IgG1; BD Biosciences San Jose, CA, USA) or antibodies recognizing HuR (Santa Cruz Biotechnology, Inc., Santa Cruz, CA, USA) for $3 \mathrm{~h}$ at $4^{\circ} \mathrm{C}$. Beads were washed with NT2 buffer $[50 \mathrm{mM}$ Tris- $\mathrm{HCl}$ ( $\mathrm{pH} 7.4$ ), $150 \mathrm{mM} \mathrm{NaCl}, 1 \mathrm{mM} \mathrm{MgCl}$ and $0.05 \%$ Nonidet P-40], incubated with 20 units RNase-free DNase I (15 min; $30^{\circ} \mathrm{C}$ ) and further incubated in $100 \mu \mathrm{l} \mathrm{NT} 2$ buffer containing $0.1 \%$ SDS and $0.5 \mathrm{mg} / \mathrm{ml}$ proteinase $\mathrm{K}\left(30 \mathrm{~min} ; 55^{\circ} \mathrm{C}\right)$.

RNA isolated from the IP material was reverse transcribed using random hexamers and SSII reverse transcriptase (Invitrogen Life Technologies). Transcription abundance was measured by amplification of cDNA, using quantita- tive PCR (qPCR) employing SYBR-Green PCR master mix (Applied Biosystems China, Beijing, China). PCR primers for the detection of $\mathrm{I} \kappa \mathrm{B}-\alpha$ and $\beta$-actin were as follows: I $\kappa$ B- $\alpha$ sense, 5'-GAAGAGAAGCCGCTGACCAT-3' and antisense, 5'-CAGAAGTGCCTCAGCAATTCC-3'; $\beta$-actin sense, 5'-ACGGCCAGGTCATCACTATTG-3' and antisense, 5'-AGAGGTCTTTACGGATGTCAACGT-3'.

Biotin pull-down analysis. For in vitro synthesis of biotinylated transcripts, cDNA from RAW264.7 cells was used as a template for PCR, whereby the T7 RNA polymerase promoter sequence [CCAAGCTTCTAATACGACTCACTATAGG GAGA(T7)] was added to the 5' end of all fragments. The primers used for the preparation of biotinylated transcripts spanning the 3'UTR of I $\kappa$ B- $\alpha$ (GenBank accession, no. NM_004417) and GAPDH were as follows: primers (T7), 5'-ATCGCCGTGTAATGGAAAGTGGCAAAAAGAATG-3' and 5'-GCTCTAGAGCTGTCTGTAAAAATCTGTTT

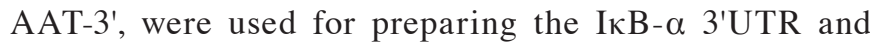
primers (T7), 5'-CAGCAAGAGCACAAGAGGAA-3' and 5'-AGGGGTCTACATGGCAACTG-3' were used to prepare the GAPDH transcripts. Biotinylated RNAs were synthesized using a MaxiScript T7 kit (Ambion, Carlsbad, CA, USA). Whole-cell lysates were incubated with $2 \mu \mathrm{g}$ purified biotinylated transcripts for $1 \mathrm{~h}$ at room temperature. Complexes were isolated with paramagnetic streptavidin-conjugated Dynabeads (Dynal ${ }^{\circledR}$, Invitrogen, Carlsbad, CA, USA) and bound proteins in the pulldown material were assayed by western blotting using antibodies against HuR (Santa Cruz Biotechnology Inc.).

mRNA stability assays. Cells were subjected to heat shock treatment for $1 \mathrm{~h}$. Following heat shock, the cells were treated with actinomycin D (5 $\mu \mathrm{g} / \mathrm{ml}$; Sigma-Aldrich) to induce transcriptional arrest. Total RNA was harvested at $0.5 \mathrm{~h}$ intervals. Control cells were maintained at $37^{\circ} \mathrm{C}$, treated with actinomycin D and harvested for total RNA isolation at $0.5 \mathrm{~h}$ intervals. Total RNA samples were subjected to qPCR as previously described (3).

Nuclear protein extraction. Nuclear extraction procedures were performed on ice. Cells were washed twice with PBS, harvested in $1 \mathrm{ml} \mathrm{PBS}$ and pelleted at 3,300 x g for $5 \mathrm{~min}$. The pellet was washed twice with PBS, resuspended in one packed cell volume of lysis buffer [10 mM HEPES, (pH 7.9), $10 \mathrm{mM} \mathrm{KCl}, 0.1 \mathrm{mM}$ EDTA, $1.5 \mathrm{mM} \mathrm{MgCl}_{2}, 0.2 \% \mathrm{v} / \mathrm{v}$ Nonidet P-40, $1 \mathrm{mM}$ DTT and $0.1 \mathrm{mM}$ PMSF] and incubated for $5 \mathrm{~min}$. Following centrifugation at 6,000 rpm, one cell pellet volume extraction buffer [20 mM HEPES, (pH 7.9), $420 \mathrm{mM}$ $\mathrm{NaCl}, 0.1 \mathrm{M}$ EDTA, $1.5 \mathrm{mM} \mathrm{MgCl} \mathrm{Mg}_{2}, 25 \%$ v/v glycerol, $1 \mathrm{mM}$ DTT and $0.5 \mathrm{mM}$ PMSF] was added to the nuclear pellet and incubated on ice for $15 \mathrm{~min}$ with occasional vortexing. Nuclear proteins were isolated by centrifugation at $14,000 \mathrm{rpm}$ for $15 \mathrm{~min}$. Protein concentrations were determined by the Bradford assay (Bio-Rad, Hercules, CA, USA) and stored at $-80^{\circ} \mathrm{C}$ for western blot analysis.

Protein stability assays. CHX (10 $\mu \mathrm{g} / \mathrm{ml}$; Sigma-Aldrich) was added to the culture medium $1 \mathrm{~h}$ following heat shock treatment and at the indicated time points $(0.5,1,2,3$ and $4 \mathrm{~h})$, 
cells were collected and protein stability was analyzed by immunoblotting.

Western blot analysis. Cells were harvested and washed twice with PBS. Harvested cells were lysed and $80 \mu \mathrm{g}$ total protein was separated by SDS-PAGE on $10 \%$ polyacrylamide gels and transferred onto nitrocellulose membranes. Following $1 \mathrm{~h}$ blocking with 5\% skimmed milk in TBS buffer (10 mM Tris and $150 \mathrm{mM} \mathrm{NaCl}$ ), membranes were incubated with primary antibodies at $4^{\circ} \mathrm{C}$ overnight. Membranes were washed four times for $15 \mathrm{~min}$ with TBST buffer (10 mM Tris, $150 \mathrm{mM} \mathrm{NaCl}$ and $0.1 \%$ Tween 20) and incubated with the appropriate HRP-conjugated secondary antibody for $1 \mathrm{~h}$ at room temperature. Protein bands were detected using an enhanced chemiluminescene western blotting detection kit (Amersham, Buckinghamshire, UK). All antibodies were purchased from Santa Cruz Biotechnology.

Immunofluorescence. Cells were washed with ice-cold PBS and fixed for $10 \mathrm{~min}$ using $4 \%$ formaldehyde in PBS. The cells were permeabilized using $0.1 \%$ Triton X-100 in PBS for $5 \mathrm{~min}$, washed with ice-cold PBS and blocked with $5 \%$ bovine serum albumin in PBS for $1 \mathrm{~h}$ at $37^{\circ} \mathrm{C}$. Subsequently, cell preparations were incubated with anti-HuR or anti-G3BP1 antibodies diluted in $5 \%$ bovine serum albumin at $4{ }^{\circ} \mathrm{C}$ (Santa Cruz Biotechnology) and underwent additional washes with ice-cold PBS, cells were incubated with a secondary antibody (Santa Cruz Biotechnology), washed with PBS and incubated with a solution of DAPI for $10 \mathrm{~min}$. Following preparation, cells were washed thoroughly and were embedded using ProLong Gold antifade reagent (Invitrogen Life Technologies). Images were captured using a fluorescence microscope (Zeiss Axiovert 35).

Statistical analysis. Data were presented as mean \pm SD of three independent assays. The statistical analysis was conducted by one-way ANOVA. $\mathrm{P}<0.05$ was considered to indicate a statistically significant difference.

\section{Results}

Heat shock increases $I \kappa B-\alpha m R N A$ and protein stability. To explore the effect of heat shock on I $\mathrm{B}-\alpha$, RAW264.7 murine macrophages were subjected to heat shock treatment. RNA and protein were extracted and examined for I $\kappa$ B- $\alpha$ mRNA and protein stability by qPCR and western blotting, respectively. The results showed that the I $\kappa$ B- $\alpha$ mRNA had a half-life of $\sim 48 \mathrm{~min}$ in untreated cells and this increased to $\sim 80 \mathrm{~min}$ following heat shock treatment (Fig. 1A). I $\mathrm{B}-\alpha$ protein had a half-life of $\sim 3 \mathrm{~h}$ (Fig. 1B) which increased to $\sim 4 \mathrm{~h}$ (Fig. 1C) following heat shock treatment. The results indicate that treatment with heat shock potently stabilizes I $\kappa$ B- $\alpha$ mRNA and proteins.

3'UTR I $\kappa$ - $\alpha$ mRNA is important for regulating the function of I $\kappa$ - $\alpha$ upon heat shock treatment. 3'-UTR mRNA may regulate the mRNA stability and translation efficiency, thus, the mechanism by which the 3'UTR of I $\kappa \mathrm{B}-\alpha$ mRNA regulates the function of I $\kappa$ B- $\alpha$ upon heat shock treatment was investigated. RAW264.7 cells were transiently transfected with a 3'UTR
A

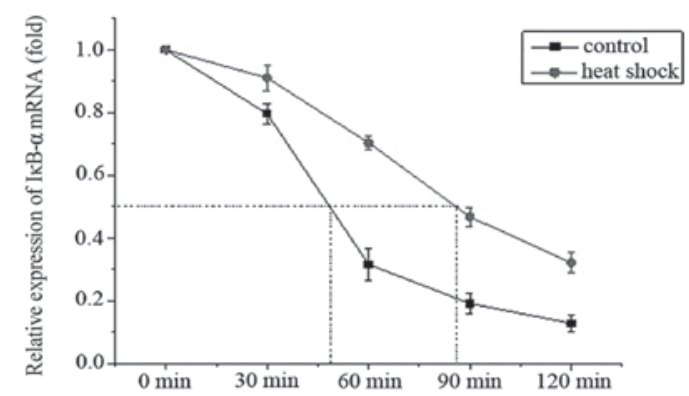

B
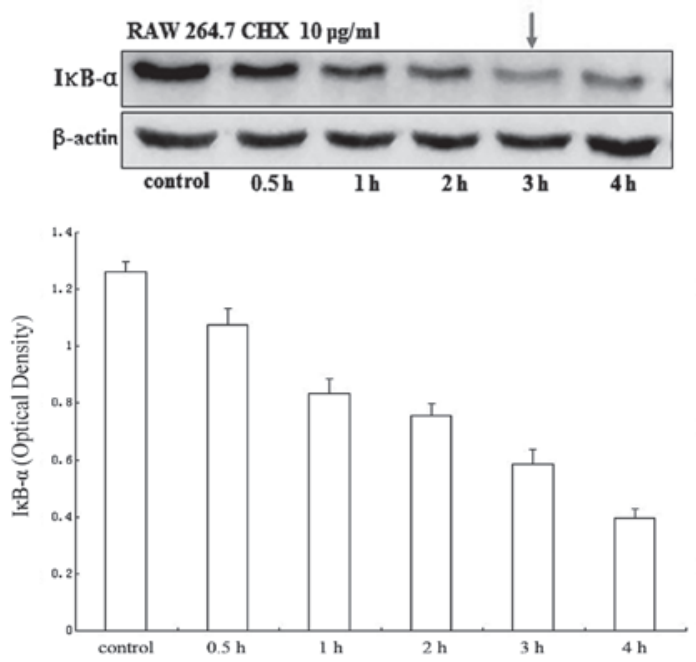

C
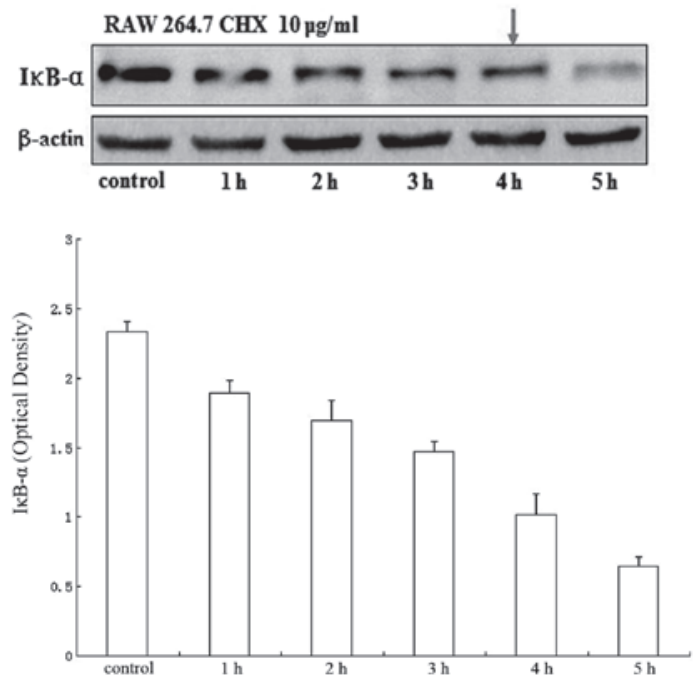

Figure 1. Alterations in I $\kappa \mathrm{B}-\alpha$ mRNA and protein stability following heat shock treatment. (A) RNA was extracted from RAW264.7 cells incubated at $43^{\circ} \mathrm{C}$ for $1 \mathrm{~h}$ and IкB- $\alpha$ mRNA stability was evaluated by qPCR and presented as fold change over actin. RAW264.7 cells were incubated with CHX (10 $\mu \mathrm{g} /$ $\mathrm{ml})$ for the indicated times to explore the half life of IкB- $\alpha$ protein (B) with and $(C)$ without heat shock. Total cell lysates were analyzed by immunoblotting using an anti-IкB- $\alpha$ antibody. $\beta$-actin was used as an internal control for protein loading. Quantification of I $\mathrm{I} B-\alpha$ protein half-life is presented below.

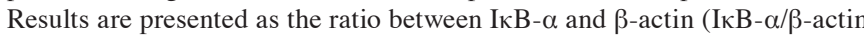
protein). Data are expressed as the mean $\pm \mathrm{SD}$ of three independent experiments.

I $\mathrm{B}-\alpha$ luciferase reporter plasmid and luciferase activity was measured in cells subjected to heat shock treatment. Exposure to heat shock significantly increased luciferase activity in transfected cells compared with cells transfected with the 


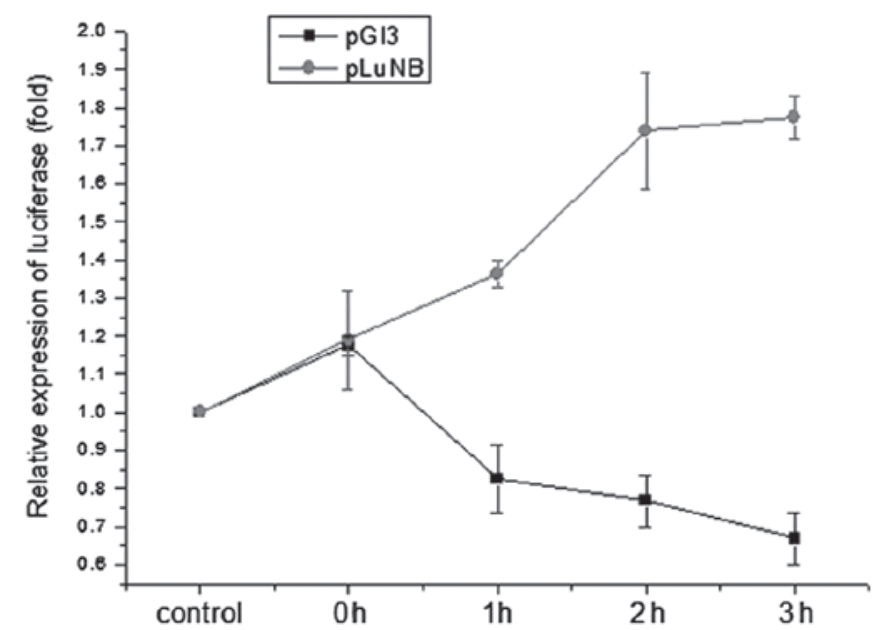

Figure 2 Luciferase activity of IкB- $\alpha$ mRNA 3'UTR following heat shock treatment. Luciferase activity in cells exposed to heat shock is expressed as relative induction over control cells (transfected with luciferase reporter control plasmid). Data are expressed as mean \pm SD of 5 individual experiments, with each experiment performed in triplicate. I $\kappa \mathrm{B}-\alpha$, inhibitor of NF- $\kappa \mathrm{B}-\alpha$; UTR, untranslated region; mRNA messenger RNA; qPCR quantitative PCR.

control plasmid (Fig. 2). These observations demonstrate that the 3'UTR of IкB- $\alpha$ mRNA exerts an important role in regulating the function of $\mathrm{I} \kappa \mathrm{B}-\alpha$ upon heat shock treatment.

$H u R$ binds to endogenous and recombinant I $\kappa B-\alpha m R N A$. The I $\mathrm{B}-\alpha$ mRNA has a long AU-rich 3'UTR containing a number of predicted hits of a previously identified HuR motif. Thus, we determined whether I $\mathrm{B}-\alpha$ mRNA is the target of HuR in mRNA stabilization and/or translation and if such RNA protein associations changed in a heat shock-dependent manner. First, the existence of such RNA binding protein was analyzed by employing a biotin pull-down assay. Following the pull-down assay using streptavidin-coated beads, western blotting analysis revealed that $\mathrm{HuR}$ associates specifically with IкB- $\alpha$ 3'UTR transcripts but not with GAPDH 3'UTR transcripts (Fig. 3A).

RNP IP analysis was then performed to investigate the association of endogenous HuR with endogenous mRNAs. Using lysates from untreated RAW264.7 cells, RNP IP assays revealed an $\sim 11$-fold enrichment in I $\kappa$ B- $\alpha$ mRNA associated with HuR in anti-HuR antibody IP reactions compared with the control IgG IP reactions. Using lysates from heat shock-treated cells, the association of MKP-1 mRNA with HuR was $>45$-fold higher than that observed in control cells (Fig. 3B). As a negative control, the abundance of housekeeping GAPDH mRNA in HuR IP samples was comparable with that observed following IgG IP and remained unchanged by heat shock treatment (Fig. 3B). The relative enrichment of these mRNAs in each RNP IP reaction was also investigated by qPCR, followed by conventional PCR amplification and visualization on agarose gels (Fig. 3B).

HuR affects the function of the I $\kappa B-\alpha$ mRNA 3'UTR. To determine the role of HuR in heat shock-mediated regulation of the I $\mathrm{B}-\alpha$ mRNA 3'UTR, NIH 3T3 cells were transiently cotransfected with the 3 'UTR of I $\kappa$ B- $\alpha$ luciferase reporter plasmid and flag-HuR plasmid as described and luciferase activity was
A

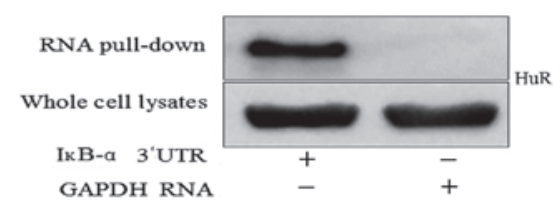

B
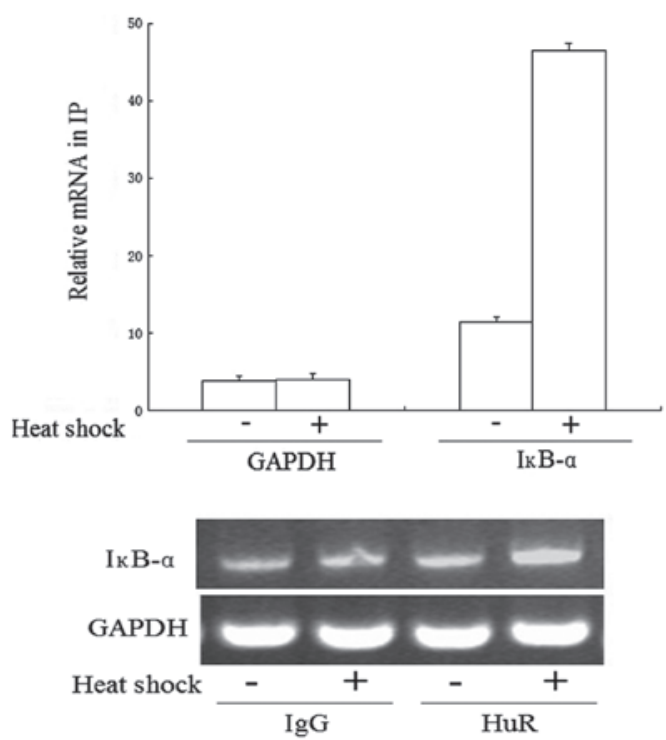

C

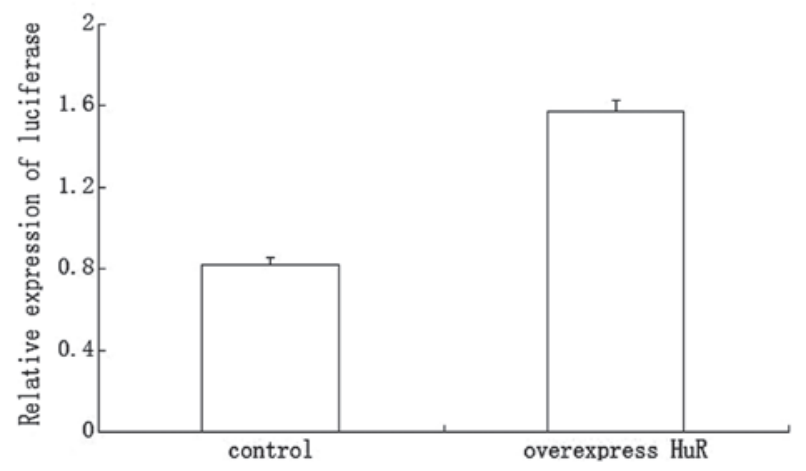

Figure 3. HuR binds to endogenous and recombinant I $\kappa \mathrm{B}-\alpha$ mRNA and regulates the function of I $\kappa$ B $-\alpha$ mRNA 3'UTR. (A) Biotinylated I $\kappa$ B- $\alpha$ mRNA 3'UTR and a negative control biotinylated GAPDH 3'UTR fragment were prepared and their associations with HuR were tested by biotin pull-down assay using lysates from RAW cells. The results presented are representative western blotting signals using specific antibodies against HuR. (B) Binding of endogenous HuR with endogenous mRNAs was detected by qPCR analysis of material obtained by IP from cytoplasmic fractions of untreated or heat shock-treated $(1 \mathrm{~h})$ cells using anti-IgG and anti-HuR antibodies. IкB- $\alpha$ mRNA present in the IP material was detected by qPCR analysis and presented as fold differences in abundance of the corresponding mRNAs in the RNA-BPs IP compared with those of the IgG IP. qPCR results are presented as mean \pm SD from three independent experiments. (C) RAW264.7 murine macrophages were transiently cotransfected with IкB- $\alpha$ 3'UTR luciferase reporter plasmid and (flag)-tagged HuR plasmid and subjected to heat shock $\left(43^{\circ} \mathrm{C}\right.$ for $\left.1 \mathrm{~h}\right)$. Luciferase activity in cells exposed to heat shock is expressed as relative induction over control cells [cotransfected with luciferase reporter control plasmid and (flag)-tagged HuR plasmid]. Data are presented as mean $\pm \mathrm{SD}$ of 2 individual experiments, with each experiment performed in triplicate. I $\mathrm{B}-\alpha$, inhibitor of $\mathrm{NF}-\kappa \mathrm{B}-\alpha$; UTR, untranslated region; mRNA messenger RNA; qPCR quantitative PCR.

measured following heat shock treatment. Overexpression of HuR increased luciferase activity compared with the control group cotransfected with luciferase reporter control plasmid and flag-HuR plasmid (Fig. 3C). 
A

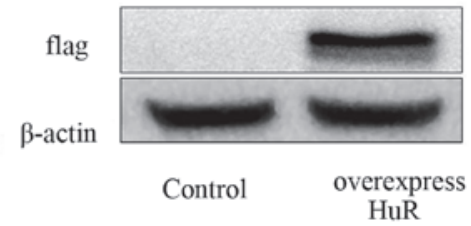

B
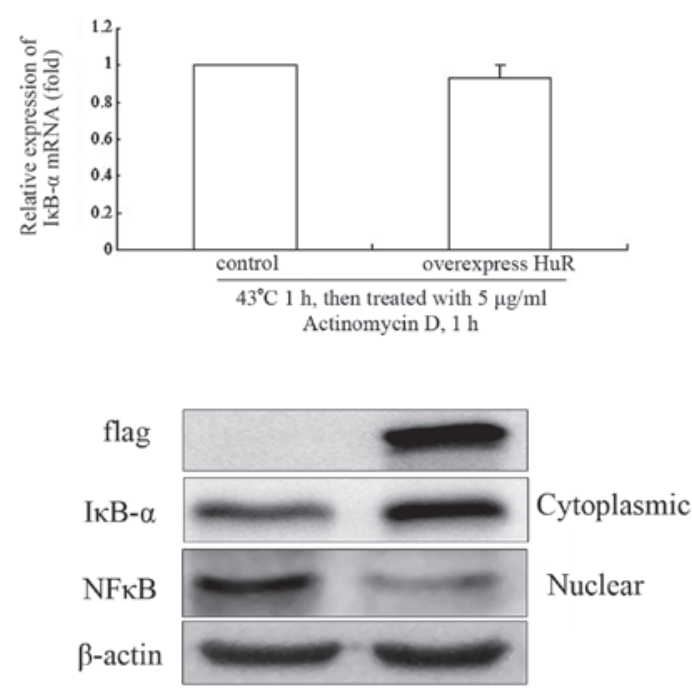

C

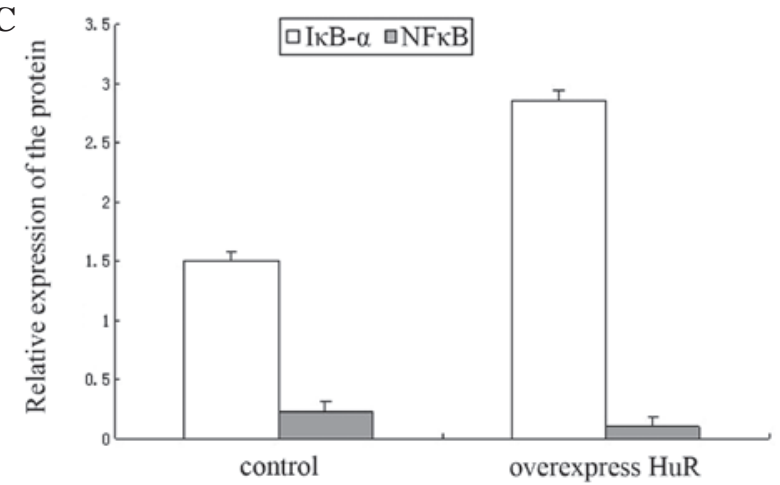

Figure 4. Overexpression of HuR alters IкB- $\alpha$ mRNA stability and protein expression. (A) $3 \mathrm{~T} 3$ cells were transfected with (flag)-tagged-HuR plasmid for $48 \mathrm{~h}$ and (flag)-tagged-HuR protein levels were analyzed by western blotting. $\beta$-actin was used as an internal control for protein loading. (B) 3T3 cells were transfected with (flag)-tagged-HuR plasmid for $48 \mathrm{~h}$ and underwent heat shock treatment for $1 \mathrm{~h}$. The control group was transfected with pcDNA3-control plasmid and maintained at $37^{\circ} \mathrm{C}$. mRNA stability was evaluated by qPCR and presented as fold change over actin. (C) 3 T3 cells were transfected with (flag)-tagged-HuR plasmid for $48 \mathrm{~h}$. Protein was extracted from the $3 \mathrm{~T} 3$ cells and examined for (flag)-tagged-HuR protein, I $\mathrm{B}-\alpha, N F-\kappa B$ by western blotting. $\beta$-actin was used as internal control for protein loading. Results are presented as the ratio of protein and $\beta$-actin (protein/ $\beta$-actin protein). Quantification of the proteins are presented in the graphics below. Data are presented as mean \pm SD with each experiment

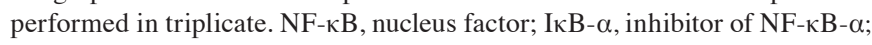
mRNA messenger RNA; qPCR quantitative PCR.

Effect of overexpression of HuR on I $\kappa$ B- $\alpha$ mRNA stability and protein expression. To explore the effect of HuR on the regulation of IкB- $\alpha$ at the post-transcriptional level, NIH 3T3 cells were transfected with flag-HuR plasmid for $48 \mathrm{~h}$ and

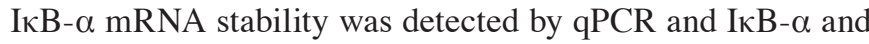
NF- $\kappa B$ protein by western blotting. The flag-HuR plasmid was expressed at high levels in NIH 3T3 cells (Fig. 4A). There was little change in IKB- $\alpha$ mRNA stability following heat shock treatment (Fig. 4B). Overexpression of HuR may increase the
A

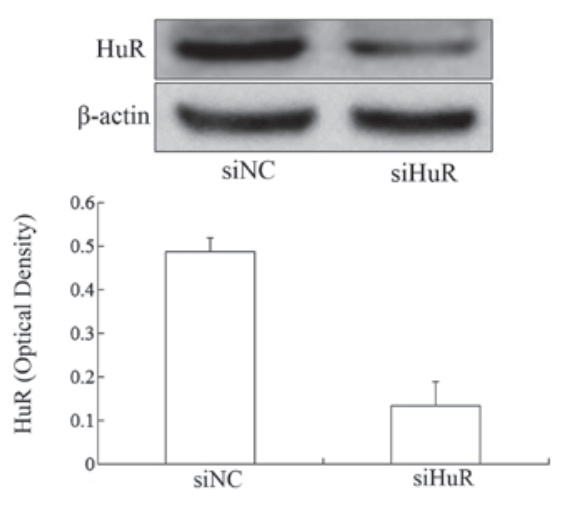

B

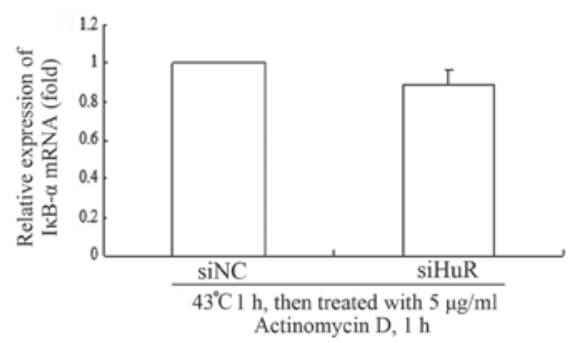

C
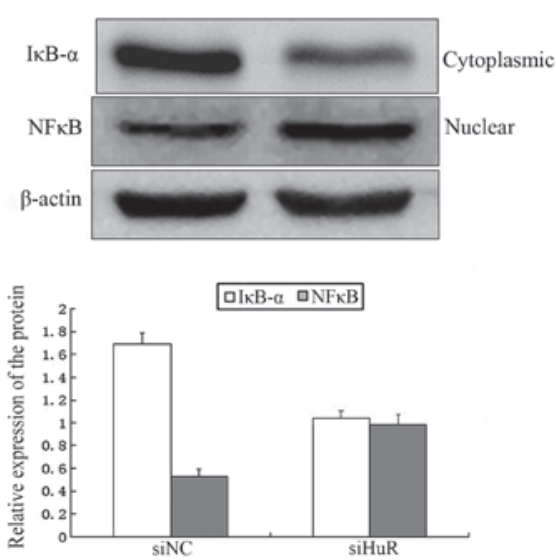

Figure 5. siRNA interference of HuR alters I B $-\alpha$ mRNA stability and protein expression. (A) $3 \mathrm{~T} 3$ cells were transfected with siRNAs targeting HuR or with a negative control siRNA for $48 \mathrm{~h}$. Protein was extracted from the 3T3 cells and examined for HuR protein by western blotting. $\beta$-actin was used as an internal control for protein loading. Results are presented as the ratio of $\mathrm{HuR}$ and $\beta$-actin (HuR/ $\beta$-actin protein). (B) $3 T 3$ cells with siRNA interference of HuR were exposed to heat shock for $1 \mathrm{~h}$. Control cells transfected with a negative control siRNA for $48 \mathrm{~h}$ and maintained at $37^{\circ} \mathrm{C}$. mRNA stability was evaluated by qPCR and presented as fold change over actin. (C) 3T3 cells were transfected with siRNAs targeting HuR and the control group was transfected with a negative control siRNA for $48 \mathrm{~h}$. Protein was extracted from the $3 \mathrm{~T} 3$ cells and examined for IкB- $\alpha$ and NF- $\kappa \mathrm{B}$ by western blotting using anti-IкB- $\alpha$ and anti-NF- $\mathrm{\kappa B}$ antibodies. $\beta$-actin was used as internal control for protein loading. Results are presented as the ratio between protein and $\beta$-actin (protein/ $\beta$-actin protein). Quantification of the proteins are presented below each blot. Data are presented as mean $\pm \mathrm{SD}$ with each experiment performed

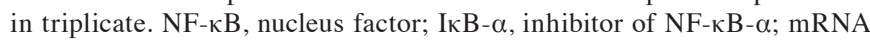
messenger RNA; qPCR quantitative PCR siRNA, small interfering RNAs.

expression of IкB- $\alpha$ protein. IкB- $\alpha$ protein increased by $\sim 50 \%$ compared with the control group. NF- $\kappa B$ protein levels in the nucleus were decreased by $\sim 55 \%$ (Fig. 4C).

Effect of HuR on I $\mathrm{KB}-\alpha$ mRNA stability and protein expression. NIH 3T3 cells were transfected with siRNA specifically targeting HuR for $48 \mathrm{~h}$. The results revealed that HuR protein 


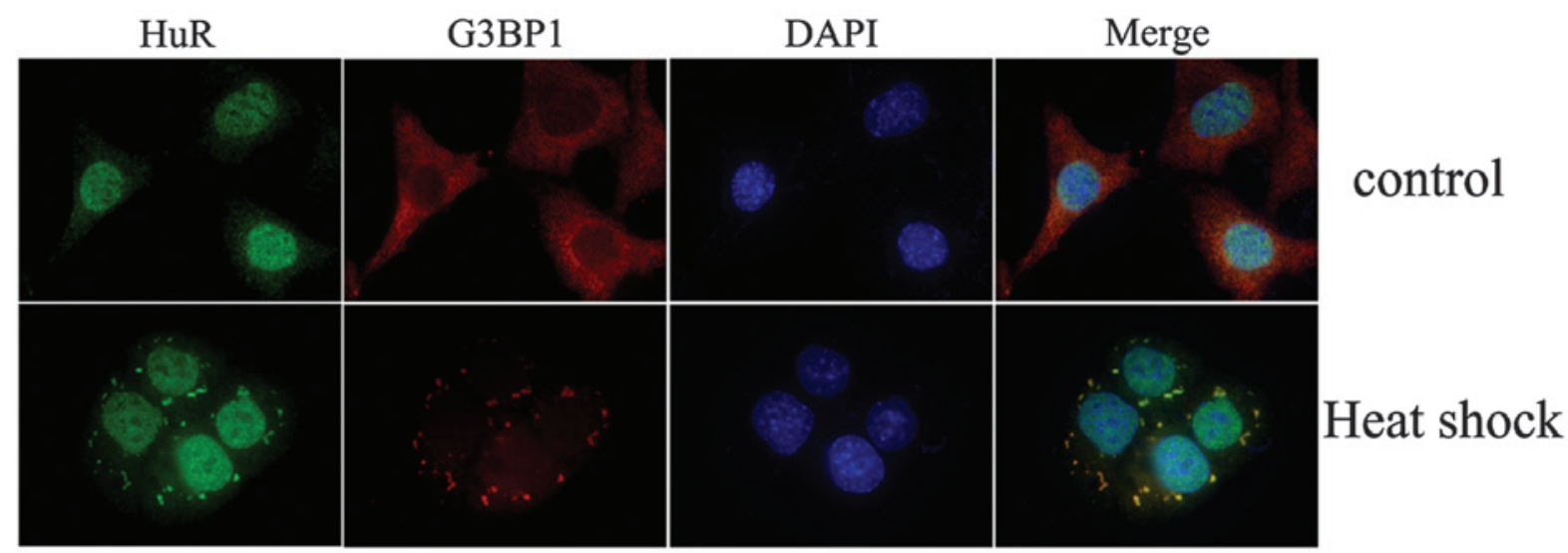

Figure 6. Changes in subcellular distribution of HuR in 3T3 cells upon heat shock treatment. 3T3 cells were stained with monoclonal antibody against HuR (green) and antibody for G3BP1 (red), counter stained with DAPI (blue). Representative images of three independent experiments are presented.

decreased by $\sim 75 \%$ (Fig. 5A). There was little effect on IкB- $\alpha$ mRNA stability following heat shock treatment (Fig. 5B). IкB- $\alpha$ protein levels decreased by $\sim 40 \%$ compared with the control group and the nuclear NF- $\mathrm{kB}$ protein levels increased by $\sim 50 \%$ (Fig. 5C).

Subcellular distribution changes of HuR. To investigate whether HuR undergoes nucleus-to-cytoplasmic shuttling upon heat shock treatment, NIH 3T3 cells were treated by heat shock for $1 \mathrm{~h}$. It was observed that HuR was primarily localized in the nucleus and G3BP1 was primarily localized in the cytoplasm of resting cells, whereas relocalization of $\mathrm{HuR}$ from the nucleus to the cytoplasm was observed following $1 \mathrm{~h}$ of heat shock treatment. HuR was observed to colocalize with G3BP1 protein to form stress granules (SGs; Fig. 6).

\section{Discussion}

It has been established that preconditioning with heat shock treatment confers protection against inflammation-associated tissue and organ injury $(7,8)$. Accordingly, the mechanisms by which heat shock modulates inflammation-associated signal transduction were investigated, particularly in cells of the monocyte/macrophage line. The present study focused on the $\mathrm{I} \kappa \mathrm{B} / \mathrm{NF}-\kappa \mathrm{B}$ pathway, clearly demonstrating that heat shock inhibits NF- $\mathrm{KB}$ activation in vitro and in vivo, in agreement with Malhotra and Wong (9). The mechanisms which govern this modulation have been of particular interest.

Activation of the NF- $\mathrm{KB}$ pathway results in the expression of inflammatory and immune response genes. These signals must be transient and well regulated as prolonged NF- $\mathrm{KB}$ activation may lead to abnormal gene expression and the deregulation of NF- $\mathrm{kB}$ activation has been involved in various pathologies, including chronic inflammation and cancer. The biological importance of the IкBs as negative feedback regulators in NF- $\mathrm{KB}$ signaling has been established. The expression

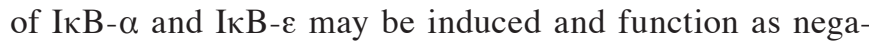
tive feedback regulators of NF- $\kappa \mathrm{B}$. IкB- $\alpha$ knockouts cause mortality 7-10 days following birth due to hyperinflammation (10). In addition, mice with mutated $\kappa B$ enhancers of the IкB- $\alpha$ promoter exhibit a shortened life span (13-15 months), hypersensitivity to septic shock and abnormal T-cell development/activation (11). Negative feedback limits the duration of stimulus-induced NF- $\mathrm{\kappa B}$ activity and the magnitude of the gene expression response, but may also mediate the transduction of stimulus-specific information via a 'temporal signaling code' that determines which of the many possible target genes are activated in response to a specific stimulus. IкB- $\alpha$ deficiency results in inappropriate gene expression (12). The distinct degradation pathways between the free and bound IкBs result in highly dynamic homeostatic control of the NF- $\kappa B$ signaling module, which imparts functional robustness to this signaling system.

Eukaryotes employ multiple post-transcriptional mechanisms to adjust their gene expression programs in response to external cues and changes in the physiological status of the cell $(13,14)$. A major role in post-transcriptional hierarchy is played by RNA-binding proteins (RBPs) that regulate virtually every aspect of mRNA metabolism, from nuclear processing reactions and export to the cytoplasm to translation and stability $(15,16)$. HuR is one of the most popular RBPs. HuR associates with mRNAs bearing U/AU-rich sequences, typically present in 3 'UTRs (17). The I $\kappa \mathrm{B}-\alpha$ mRNA possesses a long, AU-rich 3'UTR, containing predicted binding sites of an HuR motif, thus, the RNA binding protein HuR was selected as a target. RNA pull-down and RNP IP was employed to investigate the association between HuR and IкB- $\alpha$ mRNA. HuR was observed to be associated specifically with IkB- $\alpha$ 3'UTR transcripts upon heat shock treatment and RNP IP assays revealed a 45 -fold enrichment in IкB- $\alpha$ mRNA associates with HuR in anti-HuR antibody IP reactions relative to that of control IgG IP reactions. These observations indicate that HuR associates prominently with IкB- $\alpha$ mRNA following heat shock treatment. In addition, the effect of HuR on the regulation of IкB- $\alpha$ at the post-transcriptional level was investigated. The results showed that overexpression of HuR increases the expression of IкB- $\alpha$ protein which, in turn, decreases NF- $\kappa \mathrm{B}$ in the nucleus. Knockdown of HuR decreased I $\mathrm{IK}-\alpha$ protein levels, increasing NF- $\kappa \mathrm{B}$ in the nucleus, but had little effect on the stability of IкB- $\alpha$ mRNA.

Although HuR is located predominantly in the nucleus, its post-transcriptional effect is linked to its translocation to the cytoplasm, where it stabilizes and/or modulates the translation of numerous target mRNAs. Changes in the subcellular 
distribution of HuR upon heat shock treatment was observed. The results indicate that $\mathrm{HuR}$ is primarily located in the nucleus without heat shock treatment and translocates to the cytoplasm with heat shock where HuR and G3BP1 protein colocalize. G3BP1 proteins are the main content of the SG (18). SGs typically contain stalled mRNAs, 40S ribosomal subunits and a number of translational initiation factors, including eIF2 and eIF3 and RNA binding proteins.

In the present study, HuR was demonstrated to translocate between the nucleus and the cytoplasm, binding to the IкB- $\alpha$ mRNA upon heat shock treatment. HuR was observed to modulate the translation of I $\kappa \mathrm{B}-\alpha$ mRNA without affecting the half-lives. The exact mechanism by which HuR modulates the translation of $\mathrm{I} \kappa \mathrm{B}-\alpha$ mRNA and the effect on the NF- $\kappa \mathrm{B}$ pathway remain to be elucidated.

\section{Acknowledgements}

Financial support was provided by grants from the National Science Foundation of China (no. 81171476), Natural Science Funds for Distinguished Youth Team of Zhejiang Province (no. R2101166), the Scientific Innovation Team Project of Ningbo, China (no. 2011B82014) China and the Scientific Project of Ningbo, China (no. XKL11D2116). Sponsored by K.C. Wong Magna Fund of Ningbo University, Ningbo, China.

\section{References}

1. Shanley TP, Ryan MA, Eaves-Pyles T and Wong HR: Heat shock inhibits phosphorylation of IkappaBalpha. Shock 14: 447-450, 2000.

2. Grossman BJ, Shanley TP, Odoms K, Dunsmore KE, Denenberg AG and Wong HR: Temporal and mechanistic effects of heat shock on LPS-mediated degradation of IkappaBalpha in macrophages. Inflammation 26: 129-137, 2002.

3. Kohn G, Wong HR, Bshesh K, Zhao B, Vasi N, Denenberg A, Morris C, Stark J and Shanley TP: Heat shock inhibits tnf-induced ICAM-1 expression in human endothelial cells via Ikappakinase inhibition. Shock 17: 91-97, 2002.
4. Pittet JF, Lee H, Pespeni M, O'Mahony A, Roux J and Welch WJ: Stress-induced inhibition of the NF-kappaB signaling pathway results from the insolubilization of the IkappaB kinase complex following its dissociation from heat shock protein 90 . J Immunol 174: 384-394, 2005.

5. Deng L, Wang C, Spencer E, Yang L, Braun A, Slaughter C, Pickart $C$ and Chen ZJ: Activation of the IkappaB kinase complex by TRAF6 requires a dimeric ubiquitin conjugating enzyme complex and a unique polyubiquitin chain. Cell 103: 351-361, 2000.

6. Ouaaz F, Arron J, Zheng Y, Choi Y and Beg AA: Dendritic cell development and survival require distinct NF-kappaB subunits. Immunity 16: 257-270, 2002.

7. Wong HR: Potential protective role of the heat shock response in sepsis. New Horiz 6: 194-200, 1998.

8. Wong HR and Wispé JR: The stress response and the lung. Am J Physiol Lung 273: L1-L9, 1997.

9. Malhotra V and Wong HR: Interactions between the heat shock response and the nuclear factor-kappaB signaling pathway. Crit Care Med 30 (1 Supp): S89-S95, 2002.

10. Beg AA, Sha WC, Bronson RT and Baltimore D: Constitutive NF-kappaB activation, enhanced granulopoiesis and neonatal lethality in IkappaBalpha-deficient mice. Genes Dev 9: 2736-2746, 1995

11. Peng B, Ling J, Lee AJ, Wang Z, Chang Z, Jin W, Kang Y, Zhang R, Shim D, Wang H, Fleming JB, Zheng H, Sun SC and Chiao PJ: Defective feedback regulation of NF-kappaB underlies Sjogren's syndrome in mice with mutated kappaB enhancers of the IkappaBalpha promoter. Proc Natl Acad USA 107: 15193-15198, 2010.

12. Hoffmann A, Levchenko A, Scott ML and Baltimore D: The IkappaB-NF-kappaB signaling module: temporal control and selective gene activation. Science 298: 1241-1245, 2002.

13. Moore MJ: From birth to death: the complex lives of eukaryotic mRNAs. Science 309: 1514-1518, 2005.

14. Moore MJ and Proudfoot NJ: Pre-mRNA processing reaches back to transcription and ahead to translation. Cell 136: 688-700, 2009.

15. Glisovic T, Bachorik JL, Yong J and Dreyfuss G: RNA-binding proteins and post-transcriptional gene regulation. FEBS Lett 582: 1977-1986, 2008

16. Sanchez-Diaz P and Penalva LO: Post-transcription meets post-genomic: the saga of RNA binding proteins in a new era. RNA Biol 3: 101-109, 2006.

17. López de Silanes I, Zhan M, Lal A, Yang X and Gorospe M: Identification of a target RNA motif for RNA-binding protein HuR. Proc Natl Acad USA 101: 2987-2992, 2004.

18. Anderson P and Kedersha N: Stressful initiations. Cell 115: 3227-3234, 2002 